\title{
Soluble $\alpha$-klotho as a potential predictor of all-cause mortality in Chinese maintenance hemodialysis patients
}

Junping Liu, Dongping Shi, Xiaohui Song, Yahong Ji

Department of Nephrology, Fenyang Hospital of Shanxi Province, China

Submitted: 9 July 2021; Accepted: 21 December 2021

Online publication: 28 January 2022

Arch Med Sci

DOI: https://doi.org/10.5114/aoms/145779

Copyright $\odot 2022$ Termedia \& Banach

\section{Abstract}

Introduction: This study aimed to clarify the potential association of serum soluble $\alpha$-klotho levels with all-cause mortality in Chinese patients on maintenance hemodialysis (MHD).

Material and methods: The present study is a single-center prospective cohort study. It included 134 MHD patients who were divided into two groups according to the median level of serum $\alpha$-klotho: 68 patients in the low soluble $\alpha$-klotho group $(<1.15 \mathrm{ng} / \mathrm{ml}$ and equivalent to $1.15 \mathrm{ng} / \mathrm{ml})$ and 66 patients in the high soluble $\alpha$-klotho group $(>1.15 \mathrm{ng} / \mathrm{ml})$. These patients were followed up for 36 months. The three-year all-cause mortality rate, overall survival (OS) and cardio-cerebrovascular mortality were observed. The potential risk factors of all-cause mortality in MHD patients were investigated by Cox regression models.

Results: The 3 -year all-cause mortality rates in the low soluble $\alpha$-klotho group were significantly higher than those in the high soluble $\alpha$-klotho group $(33.82 \%$ vs. $16.67 \%, p=0.039)$. The difference of the 3 -year cardio-cerebrovascular mortality rates between the two groups was non-significant $(26.47 \%$ vs. $15.15 \%, p=0.107)$. The Kaplan-Meier analysis showed that the differences in the rates of OS and cardio-cerebrovascular death free survival between the two groups were significantly different (all $p<0.05$ ). The Cox regression analyses revealed that low soluble $\alpha$-klotho level was an independent predictor of all-cause mortality in MHD patients after adjusting for potential confounding factors.

Conclusions: Low serum soluble $\alpha$-klotho levels were associated with increased risk of all-cause mortality in Chinese MHD patients.

Key words: $\alpha$-klotho, maintenance hemodialysis, mortality, overall survival, Cox regression.

\section{Introduction}

$\alpha$-Klotho is a novel protein mainly expressed in the kidney, brain and parathyroid [1]. It was first found by Kuro-o et al. in 1997 as an anti-ageing protein due to the fact that $\alpha$-klotho deficient mice resembled human premature-aging syndrome [2]. But it was demonstrated that the anti-ageing effect of $\alpha$-klotho was associated with its protective role in avoiding excess dietary phosphate intake [3, 4]. There are 2 forms of klotho protein: a soluble form and a membrane form. The membrane $\alpha$-klotho is the specific receptor of fibroblast growth factor

\author{
Corresponding author: \\ Junping Liu \\ Department of Nephrology \\ Fenyang Hospital \\ of Shanxi Province \\ 186 Shengli St \\ Fenyang, Shanxi Province, \\ 032200, China \\ Phone: +86-15035823930 \\ Fax: +86-0358-7222225 \\ E-mail: LiuJunp_223@126.com
}


23 (FGF23), a hormone mainly produced by osteoblasts and osteocytes [3]. The FGF23-klotho endocrine system plays an important role in regulating phosphate absorption, maintaining mineral homeostasis, inhibiting 1,25-dihydroxy vitamin $D$ $\left[1,25(\mathrm{OH})_{2} \mathrm{D}_{3}\right]$ activity and suppressing synthesis of parathyroid hormone $[1,5,6]$. The proteolytic release of the transmembrane $\alpha$-klotho generates the soluble form of $\alpha$-klotho. It has been found that soluble $\alpha$-klotho, which could be detected in plasma, urine, and cerebrospinal fluid, is a humoral factor to regulate glycoproteins on the cell surface independently of FGF-23 [7]. Soluble $\alpha$-klotho has multiple functions including regulating ion channels and reducing oxidative stress $[1,5]$.

The kidney has been thought to be the main source of $\alpha$-klotho [8]. Genetic studies demonstrated that klotho gene deficiency resulted in phenotypes prone to the development of kidney disease including acute kidney injury (AKI) and chronic kidney disease (CKD) [9]. In addition, the development of kidney disease could also lead to the decreased expression of $\alpha$-klotho [10, 11]. Animal models of CKD had lower $\alpha$-klotho levels in kidney tissue and lower circulating soluble $\alpha$-klotho in serum than normal animals [8]. Thus, soluble $\alpha$-klotho was regarded as a protective factor against kidney disease and its complications $[5,7]$.

Maintenance hemodialysis (MHD) is currently the main treatment for end-stage renal disease (ESRD). Patients' maintenance dialysis was affected by body mass decomposition and hydration state imbalances, and it is closely related to depressive symptoms $[12,13]$. Compared with CKD patients not undergoing dialysis, MHD patients had highly decreased soluble $\alpha$-klotho levels [14]. Cardiovascular disease and cerebrovascular disease are common hemodialysis-associated complications. In previous studies, soluble $\alpha$-klotho was demonstrated to be associated with cardiovascular events and cerebrovascular disease during MHD [14-16]. In 2015, Otani-Takei et al. found that serum soluble $\alpha$-klotho levels below $309 \mathrm{pg} / \mathrm{ml}$ had significantly higher all-cause and cardiovascular mortality rates in Japanese patients on MHD [17]. However, information regarding the impact of soluble $\alpha$-klotho levels on all-cause mortality rates in Chinses MHD patients still remains scarce. Thus, we conducted this prospective study to evaluate the predictive value of soluble $\alpha$-klotho levels for mortality in Chinese MHD patients.

\section{Material and methods}

\section{Patients}

The present study was a single-center prospective cohort study which was approved by the Institutional Review Board of our hospital in ac- cordance with the provisions of the Declaration of Helsinki. Between January 2017 and January 2018, a total of 150 patients from the Dialysis Center of our hospital were screened in this study. The inclusion criteria were as follows: (1) patients whose age was 18 years or older; (2) patients who received MHD for at least 3 months; (3) patients who voluntarily participated in the study. Patients were excluded if they had an active malignancy, had an active psychiatric disorder, had acute inflammation or autoimmune disease, or underwent peritoneal dialysis. Informed consent was obtained from all patients included in this study.

\section{Data collection}

The baseline parameters, including sex, age, height, weight and primary diseases, were recorded. The body mass index (BMI) was calculated from the weight and height. The fasting blood samples were obtained in the morning and pre-dialysis on the first day the patients enrolled in this study. Blood pressure (BP) was measured in a sitting position in the non-fistula arm before dialysis. All patients were followed up for 36 months (the first patient was enrolled in January 2017 and the last patient was enrolled in January 2018; after 36 months of follow-up, the last patient ended the study in January 2021) or until the date of death or loss to follow-up. The outcomes of this study included: (1) the 3-year all-cause mortality rate; (2) overall survival (OS), which was defined as the time from the day the patients enrolled to the date of death for any reason; (3) cardio-cerebrovascular mortality, which was defined as death from any cardio-cerebrovascular event.

\section{Laboratory analyses}

Hemoglobin $(\mathrm{Hb})$ was measured by an automatic blood analyzer (Mindray, Shenzhen, China). Albumin, calcium, phosphate and alkaline phosphatase (ALP) were measured by an automatic laboratory analyzer (Olympus AU560, Hamburg, Germany). Radioimmunoassay (Beckman Coulter, California, USA) was used to detect serum parathyroid hormone (PTH) levels. The enzyme-linked immunosorbent assay (ELISA) was used to detect serum soluble $\alpha$-klotho and FGF23 levels in MHD patients. The antibodies against soluble $\alpha$-klotho and FGF23 were purchased from the technology company Xinfan Bio (Shanghai, China).

\section{Groups}

The present study is a single-center prospective cohort study. It included 134 MHD patients who were divided into two groups according to the median level of serum $\alpha$-klotho: 68 patients representing the low soluble $\alpha$-klotho group $(<1.15 \mathrm{ng} / \mathrm{ml}$ and 
equivalent to $1.15 \mathrm{ng} / \mathrm{ml}$ ) and 66 patients representing the high soluble $\alpha$-klotho group (>1.15 ng/ml).

\section{Statistical analysis}

SPSS 22.0 software was used in this study to analyze the data. Quantitative data were described as mean \pm standard deviation (SD) for normal distribution or median with interquartile range for non-normal distribution. Categorical data were described as numbers and percentages. The groups were compared using Student's $t$ test or the Kruskal-Wallis rank test for quantitative data. The $\chi^{2}$ test was used to evaluate the proportional differences in categorical data. For time-to-event variables, Kaplan-Meier curves were used and compared by log-rank tests. Cox regression models were used to investigate potential risk factors for all-cause mortality. The results of Cox regression were presented as the hazard ratio
(HR) with 95\% confidence interval $(\mathrm{Cl}) . P<0.05$ was considered as statistical significance.

\section{Results}

\section{Patients' characteristics}

In the present study, a total of 150 patients were screened. 6 patients received MHD less than 3 months, 5 patients had active malignancy or acute inflammation, and 5 patients underwent peritoneal dialysis. They were excluded from this study. Finally, the data of 134 patients were available to do the analysis. The median level of soluble $\alpha$-klotho was $1.15 \mathrm{ng} / \mathrm{mL}$ (range: $0.34-$ $2.45 \mathrm{ng} / \mathrm{ml}$ ). Thus, 68 patients were assigned to the low soluble $\alpha$-klotho group (soluble $\alpha$-klotho $\leq 1.15 \mathrm{ng} / \mathrm{ml}$ ), and 66 patients were assigned to the high soluble $\alpha$-klotho group (soluble $\alpha$-klotho $>1.15 \mathrm{ng} / \mathrm{ml}$ ). The baseline characteristic parameters of the two groups are shown in Table I.

Table I. Baseline characteristic parameters of low soluble $\alpha$-klotho group $(\leq 1.15 \mathrm{ng} / \mathrm{ml})$ and high soluble $\alpha$-klotho group (> $1.15 \mathrm{ng} / \mathrm{ml}$ )

\begin{tabular}{|c|c|c|c|c|}
\hline Baseline characteristics & Total $(n=134)$ & $\begin{array}{l}\text { Low soluble } \alpha \text {-klotho } \\
\text { group }(n=68)\end{array}$ & $\begin{array}{l}\text { High soluble } \alpha \text {-klotho } \\
\text { group }(n=66)\end{array}$ & $P$-value \\
\hline Male, $n(\%)$ & $62(46.27)$ & $32(47.06)$ & $30(45.45)$ & 0.852 \\
\hline Age [years] & $48.12 \pm 14.75$ & $45.97 \pm 14.19$ & $50.33 \pm 15.21$ & 0.088 \\
\hline BMI $\left[\mathrm{mg} / \mathrm{m}^{2}\right]$ & $22.97 \pm 2.68$ & $22.95 \pm 2.39$ & $23.00 \pm 2.87$ & 0.921 \\
\hline $\mathrm{SBP}[\mathrm{mm} \mathrm{Hg}]$ & $158.03 \pm 22.71$ & $161.44 \pm 26.14$ & $154.52 \pm 18.53$ & 0.080 \\
\hline $\mathrm{DBP}[\mathrm{mm} \mathrm{Hg}]$ & $90.10 \pm 14.83$ & $92.00 \pm 17.80$ & $88.15 \pm 11.10$ & 0.137 \\
\hline MAP [mm Hg] & $113 \pm 17.34$ & $108 \pm 18.63$ & $110 \pm 13.51$ & 0.124 \\
\hline Hemoglobin $[\mathrm{g} / \mathrm{l}]$ & $83.52 \pm 12.54$ & $83.18 \pm 12.42$ & $83.88 \pm 13.22$ & 0.753 \\
\hline Albumin $[\mathrm{g} / \mathrm{l}]$ & $38.11 \pm 4.32$ & $38.58 \pm 4.80$ & $37.62 \pm 3.71$ & 0.198 \\
\hline Serum calcium [mmol/l] & $2.07 \pm 0.28$ & $2.02 \pm 0.26$ & $2.11 \pm 0.29$ & 0.060 \\
\hline Serum phosphate $[\mathrm{mmol} / \mathrm{l}]$ & $1.89 \pm 0.32$ & $1.89 \pm 0.35$ & $1.88 \pm 0.27$ & 0.846 \\
\hline PTH [pg/ml] & $297.54 \pm 60.18$ & $298.74 \pm 61.68$ & $296.32 \pm 59.10$ & 0.817 \\
\hline $\mathrm{ALP}[\mathrm{U} / \mathrm{I}]$ & $96.90 \pm 39.01$ & $98.21 \pm 32.77$ & $95.55 \pm 50.56$ & 0.718 \\
\hline Primary diseases, $n(\%)$ & & & & 0.603 \\
\hline \multicolumn{5}{|l|}{ Uncontrolled BP, $n$ (\%): } \\
\hline $\mathrm{BP}>160 / 90$ & $80(60)$ & $43(63.2)$ & $37(56.1)$ & \\
\hline $140 / 90 \leq \mathrm{BP} \leq 160 / 90$ & $27(20)$ & $15(22.1)$ & $12(18.2)$ & \\
\hline $130 / 90 \leq \mathrm{BP}<140 / 90$ & $20(15)$ & $7(10.3)$ & $13(19.6)$ & \\
\hline $\mathrm{BP}<110 / 60$ & $7(5)$ & $3(4.4)$ & $4(6.1)$ & \\
\hline Hypertensive kidney lesions & $56(41.79)$ & $26(38.24)$ & $30(45.45)$ & \\
\hline Diabetic nephropathy & $12(8.96)$ & $8(11.76)$ & $4(6.06)$ & \\
\hline Glomerulonephritis & $44(32.84)$ & $24(35.29)$ & $20(30.30)$ & \\
\hline Polycystic kidney disease & $12(8.96)$ & $6(8.82)$ & $6(9.09)$ & \\
\hline History of cardiovascular events & $42(31.3)$ & $19(27.9)$ & $23(34.8)$ & \\
\hline Others & $10(7.46)$ & $4(5.88)$ & $6(9.09)$ & \\
\hline FGF23 [pg/ml] & $\begin{array}{c}521.21 \\
(424.34,692.13)\end{array}$ & $\begin{array}{c}580.35 \\
(454.56,697.52)\end{array}$ & $\begin{array}{c}502.52 \\
(413.75,571.45)\end{array}$ & 0.247 \\
\hline Soluble $\alpha$-klotho & $1.15(0.95,1.32)$ & $0.95(0.84,1.06)$ & $1.32(1.25,1.47)$ & $<0.001$ \\
\hline
\end{tabular}

$B M I$ - body mass index, SBP - systolic blood pressure, DBP - diastolic blood pressure, PTH - parathyroid hormone, ALP - alkaline phosphatase, FGF23 - fibroblast growth factor 23. 


\section{The effect of soluble $\alpha$-klotho on patients' mortality}

During the follow-up of three years, 34 (23.89\%) patients died. Among them, 28 (20.90\%) patients died of cardio-cerebrovascular events (18 in the low soluble $\alpha$-klotho group and 10 in the high soluble $\alpha$-klotho group), and 6 (4.48\%) patients died from non- cardio-cerebrovascular causes including infectious disease, gastrointestinal hemorrhage and carcinoma ( 5 in the low soluble $\alpha$-klotho group and 1 in the high soluble $\alpha$-klotho group). Thus, the 3-year all-cause mortality rates were $33.82 \%$ in the low soluble $\alpha$-klotho group and $16.67 \%$ in the high soluble $\alpha$-klotho group. The difference in 3 -year all-cause mortality rates between the two groups was statistically significant $\left(\chi^{2}=4.25, p=\right.$ 0.039 ). The 3 -year cardio-cerebrovascular mortality rates were $26.47 \%$ in the low soluble $\alpha$-klotho group and $15.15 \%$ in the high soluble $\alpha$-klotho group. The difference in 3-year cardio-cerebrovascular mortality rates between the two groups was not significant $\left(\chi^{2}=2.59, p=0.107\right)$.

The Kaplan-Meier analysis showed that the difference in the rates of OS between the two groups was significantly different (log-rank $p=0.019$, Figure $1 \mathrm{~A}$ ). Cumulative survival was lower in the low soluble $\alpha$-klotho group than in the high soluble $\alpha$-klotho group ( $\mathrm{HR}=2.244,95 \% \mathrm{Cl}: 1.414-4.415$, $p=0.019)$. In addition, the cardio-cerebrovascular death free survival in the low soluble $\alpha$-klotho group was also significantly lower than that in the high soluble $\alpha$-klotho group $(\mathrm{HR}=2.046,95 \% \mathrm{Cl}$ : $0.974-4.299, p=0.046$, Figure $1 \mathrm{~B}$ ).

\section{Potential risk factors for all-cause mortality}

The potential risk factors for all-cause mortality in MHD patients were analyzed by Cox regression. The results showed that patients with low soluble

A

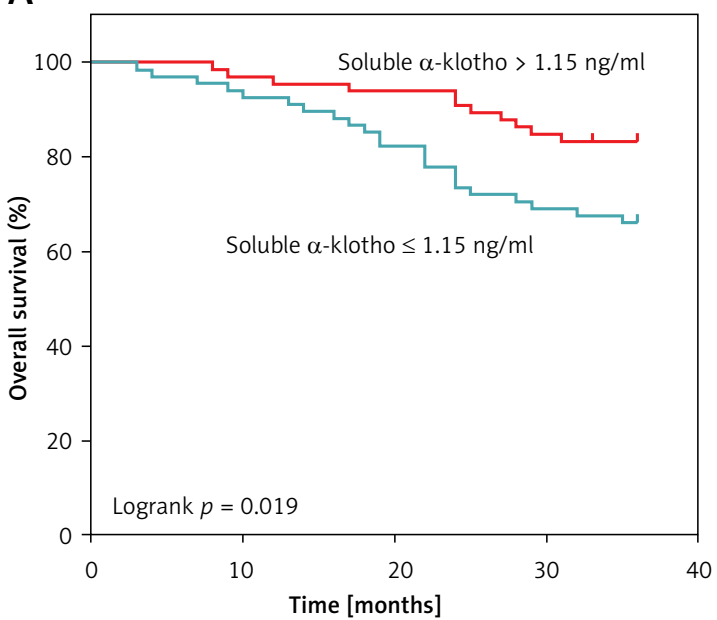

$\alpha$-klotho levels had a significantly higher risk for all-cause mortality $(\mathrm{HR}=2.324,95 \% \mathrm{Cl}: 1.070-$ 5.047, $p=0.029$ ). Serum calcium levels, serum phosphate levels and PTH levels also significantly affected all-cause mortality (Table II). After adjusting for serum calcium, serum phosphate and PTH, a low soluble $\alpha$-klotho level remained an independent predictor of all-cause mortality $(H R=2.421$, $95 \% \mathrm{Cl}: 1.082-5.417, p=0.031$ ).

\section{Discussion}

Animal studies have shown that the kidney is the main organ to produce soluble $\alpha$-klotho $[8,11]$. In living donors, the serum soluble $\alpha$-klotho levels decreased by $30 \%$ to $50 \%$ after nephrectomy [18]. Previous studies showed that serum soluble $\alpha$-klotho levels in MHD patients were significantly lower than those in healthy subjects $[16,19,20]$. The lower serum soluble $\alpha$-klotho levels were associated with more advanced CKD conditions [21, 22]. Vascular tissue is another source of soluble $\alpha$-klotho [23]. In klotho-deficiency mice, severe calcification in vascular tissues was observed [24]. Low serum soluble $\alpha$-klotho levels resulted in an increased risk of vascular calcification in dialysis patients $[25,26]$. Thus, serum soluble $\alpha$-klotho was regarded as an inhibitory factor for vascular calcification, which is a high risk factor for the survival of MHD patients [27]. Furthermore, inflammatory response and oxidative stress are linked to poor survival in MHD patients. Serum soluble $\alpha$-klotho has been reported to inhibit inflammation and oxidative stress via several mechanisms $[28,29]$. These studies suggest that $\alpha$-klotho may be closely related to mortality in MHD patients.

In 2015, Otani-Takei et al. first found that lower serum soluble $\alpha$-klotho was associated with all-cause mortality and cardiovascular mortality in MHD patients [17]. Memmos et al. reported

B

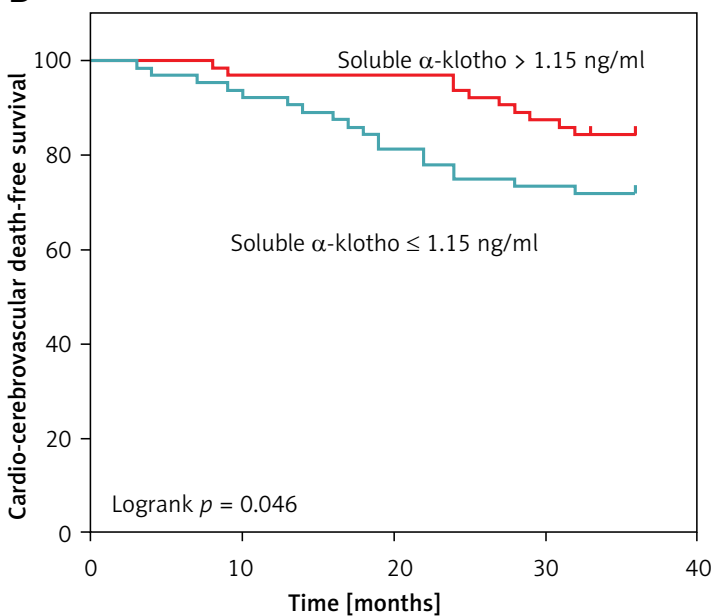

Figure 1. A - Kaplan-Meier curves of overall survival according to median soluble $\alpha$-klotho level. B - Kaplan-Meier curves of cardio-cerebrovascular death free survival according to median soluble $\alpha$-klotho level 
a study which showed that after a median follow-up of 5.5 years, patients with a low soluble $\alpha$-klotho level $(\leq 0.745 \mathrm{ng} / \mathrm{ml})$ were at increased risk of cardiovascular events and cardiovascular death [15]. Furthermore, in a cohort of 769 hemodialysis patients, patients with a soluble $\alpha$-klotho level above $0.28 \mathrm{ng} / \mathrm{ml}$ had significantly reduced rates of cardiovascular events and cardiovascular death compared to patients with soluble $\alpha$-klotho $<2.8 \times 10^{5} \mathrm{ng} / \mathrm{ml}[14]$. In China, Yu et al. analyzed the data from 211 patients on MHD and found that soluble $\alpha$-klotho level was an independent predictive factor of adverse outcomes including cardiovascular morbidity and mortality [27]. Compared with patients with soluble $\alpha$-klotho $\geq 1.34 \mathrm{ng} /$ $\mathrm{ml}$, patients with soluble $\alpha$-klotho $<1.34 \mathrm{ng} / \mathrm{ml}$ had more cardiovascular events and mortality [27]. The results of the above studies strongly supported the use of soluble $\alpha$-klotho as a prognostic factor in MHD patients.

In the present study, we found that MHD patients with lower serum soluble $\alpha$-klotho levels $(\leq 1.15 \mathrm{ng} / \mathrm{ml})$ had significantly higher 3-year allcause mortality rates and shorter overall survival. Low soluble $\alpha$-klotho level was an independent predictor of all-cause mortality in MHD patients after adjusting for potential confounding factors. Patients with low soluble $\alpha$-klotho had significantly higher 3-year all-cause mortality rates compared with patients with high soluble $\alpha$-klotho.

Cardio-cerebrovascular mortality is the main component of all-cause mortality in MHD patients, followed by infectious diseases and malignancies [30]. In this study, the 3-year cardio-cerebrovascular mortality rates between the two groups was not significant. However, the Kaplan-Meier analysis showed that cardio-cerebrovascular event free survival as well as OS in the low soluble $\alpha$-klotho group was significantly lower than that in the high soluble $\alpha$-klotho group. The reason for this difference may be related to the insufficient cardio-cerebrovascular events we have collected. The Cox regression analyses revealed that soluble $\alpha$-klotho, serum calcium, serum phosphate and PTH levels could significantly affect all-cause mortality in MHD patients. After adjusting for serum calcium, serum phosphate and PTH, a low soluble $\alpha$-klotho level remained an independent predictor of all-cause mortality. Previous studies have shown that increased levels of FGF23 were associated with poor survival of CKD patients [31, 32]. However, in this study, we did not find any correlation between FGF23 levels and all-cause mortality in MHD patients, consistent with the findings reported in Otani-Takei's study [17].

Another issue of concern is that the cut-off value to distinguish low and high soluble $\alpha$-klotho is not uniform between our study and previous studies. Otani-Takei and colleagues considered a klotho
Table II. Univariate Cox regression analyses of allcause mortality

\begin{tabular}{|lcc|}
\hline Parameters & Hazard ratio (95\% Cl) & P-value \\
\hline $\begin{array}{l}\text { Soluble } \alpha \text {-klotho } \\
\text { (low-high) }\end{array}$ & $2.324(1.070-5.047)$ & 0.029 \\
\hline $\begin{array}{l}\text { Gender } \\
\text { (male/female) }\end{array}$ & $1.076(0.509-2.276)$ & 0.848 \\
\hline Age & $0.995(0.967-1.023)$ & 0.706 \\
\hline BMI & $0.957(0.834-1.098)$ & 0.533 \\
\hline SBP & $1.010(0.995-1.025)$ & 0.196 \\
\hline DBP & $1.018(0.998-1.038)$ & 0.077 \\
\hline Hemoglobin & $1.004(0.975-1.034)$ & 0.790 \\
\hline Albumin & $0.951(0.870-1.039)$ & 0.268 \\
\hline Serum calcium & $0.316(0.153-0.654)$ & 0.002 \\
\hline Serum phosphate & $4.958(1.470-16.730)$ & 0.010 \\
\hline PTH & $1.010(1.003-1.016)$ & 0.002 \\
\hline ALP & $1.006(0.998-1.013)$ & 0.134 \\
\hline FGF23 & $0.822(0.595-1.135)$ & 0.234 \\
\hline Primary diseases & $1.143(0.897-1.457)$ & 0.281 \\
\hline BMI - body mass & index, SBP - systolic blood pressure, \\
\hline $\begin{array}{l}\text { DBP - diastolic blood } \\
\text { pressure, PTH - parathyroid hormone, }\end{array}$ \\
\hline
\end{tabular}

level of > $449 \mathrm{pg} / \mathrm{ml}$ (equivalent to $0.449 \mathrm{ng}$ / $\mathrm{ml}$ ) as high [17]. Yu et al. reported that high soluble $\alpha$-klotho level should exceed $1.34 \mathrm{ng} / \mathrm{ml}$ [27]. In this study, we found that the cut-off value to distinguish low and high soluble $\alpha$-klotho was $1.15 \mathrm{ng} / \mathrm{ml}$. The difference of detection method for soluble $\alpha$-klotho may contribute to this phenomenon. The difference in race and characteristics of enrolled patients may also result in this phenomenon.

There are several limitations to this study. First, the follow-up period of this study was not long enough. Thus, we did not collect sufficient events of all-cause death and cardio-cerebrovascular death. Second, the sample size of this study was relatively small and all patients were from a single center. Third, vascular and soft tissue calcification was not evaluated in MHD patients in this study. Thus, the correlation between soluble $\alpha$-klotho and vascular calcification is not clear. Furthermore, repeated blood samples were not taken in this study. Thus, we cannot exclude possible intraindividual variations of soluble $\alpha$-klotho levels.

In conclusion, we found that soluble $\alpha$-klotho, serum calcium, serum phosphate and PTH levels could significantly affect all-cause mortality in MHD patients. After adjusting for serum calcium, serum phosphate and PTH, a low soluble $\alpha$-klotho level remained an independent predictor of allcause mortality. Thus, serum soluble $\alpha$-klotho level could be a potential predictive factor for prognosis of patients with MHD. In this study, we found that the cut-off value to distinguish low and high soluble $\alpha$-klotho was $1.15 \mathrm{ng} / \mathrm{ml}$, but we did 
not find any correlation between FGF23 levels and all-cause mortality in MHD patients.

\section{Acknowledments}

This study was approved by the Ethics Committee of Shanxi Province Fenyang Hospital (2021022).

\section{Conflict of interest}

The authors declare no conflict of interest.

\section{References}

1. Wang QL, Su WY, Shen ZW, Wang R. Correlation between soluble $\alpha$-klotho and renal function in patients with chronic kidney disease: a review and meta-analysis. Biomed Res Int 2018; 2018: 9481475.

2. Kuro-o M, Matsumura $\mathrm{Y}$, Aizawa $\mathrm{H}$, et al. Mutation of the mouse klotho gene leads to a syndrome resembling ageing. Nature 1997; 390: 45-51.

3. Sanchez-Niño MD, Fernandez-Fernandez B, Ortiz A Klotho, the elusive kidney-derived anti-ageing factor. Clin Kidney J 2019; 13: 125-7.

4. Kurosu H, Yamamoto M, Clark JD, et al. Suppression of aging in mice by the hormone Klotho. Science 2005; 309: 1829-33.

5. Kim SM, Han A, Ahn S, Min SI, Min SK, Ha J. Klotho as a potential predictor of deceased donor kidney transplantation outcomes. Ann Surg Treat Res 2020; 98: 332-9.

6. Olauson H, Larsson TE. FGF23 and Klotho in chronic kidney disease. Curr Opin Nephrol Hypertens 2013; 22: 397-404.

7. Gołembiewska E, Stepniewska J, Kabat-Koperska J, Kędzierska K, Domański M, Ciechanowski K. The role of klotho protein in chronic kidney disease: studies in animals and humans. Curr Protein Pept Sci 2016; 17: 821-6.

8. Drew DA, Katz R, Kritchevsky S, et al. Association between soluble klotho and change in kidney function: the health aging and body composition study. J Am Soc Nephrol 2017; 28: 1859-66.

9. Izquierdo MC, Perez-Gomez MV, Sanchez-Niño MD, et al. Klotho, phosphate and inflammation/ageing in chronic kidney disease. Nephrol Dial Transplant 2012; 27 Suppl 4: iv6-10.

10. Lindberg K, Amin R, Moe OW, et al. The kidney is the principal organ mediating klotho effects. J Am Soc Nephrol 2014; 25: 2169-75.

11. Hu MC, Shi M, Zhang J, et al. Renal production, uptake, and handling of circulating aklotho. J Am Soc Nephrol 2016; 27: 79-90.

12. Hoppe K, Schwermer K, Kawka A, et al. Dialysis vintage stratified comparison of body composition, hydration and nutritional state in peritoneal dialysis and hemodialysis patients. Arch Med Sci 2018; 14: 807-17.

13. Kusztal M, Trafidło E, Madziarska K, et al. Depressive symptoms but not chronic pain have an impact on the survival of patients undergoing maintenance hemodialysis. Arch Med Sci 2018; 14: 265-75.

14. Marçais C, Maucort-Boulch D, Drai J, et al. Circulating klotho associates with cardiovascular morbidity and mortality during hemodialysis. J Clin Endocrinol Metab 2017; 102: 3154-61.
15. Memmos E, Sarafidis P, Pateinakis P, et al. Soluble Klotho is associated with mortality and cardiovascular events in hemodialysis. BMC Nephrol 2019; 20: 217.

16. Wei H, Li H, Song X, et al. Serum klotho: a potential predictor of cerebrovascular disease in hemodialysis patients. BMC Nephrol 2019; 20: 63.

17. Otani-Takei N, Masuda T, Akimoto T, et al. Association between serum soluble klotho levels and mortality in chronic hemodialysis patients. Int J Endocrinol 2015; 2015: 406269.

18. Akimoto T, Kimura T, Watanabe $Y$, et al. The impact of nephrectomy and renal transplantation on serum levels of soluble Klotho protein. Transplant Proc 2013; 45: 134-6.

19. Zhang AH, Guo WK, Yu L, Liu WH. Relationship of serum soluble klotho levels and echocardiographic parameters in patients on maintenance hemodialysis. Kidney Blood Press Res 2019; 44: 396-404

20. Yokoyama K, Imura A, Ohkido I, et al. Serum soluble $\alpha$-klotho in hemodialysis patients. Clin Nephrol 2012; 77: 347-51.

21. Bi X, Yang K, Zhang B, Zhao J. The protective role of klotho in CKD-associated cardiovascular disease. Kidney Dis (Basel) 2020; 6: 395-406.

22. Zou D, Wu W, He Y, Ma S, Gao J. The role of klotho in chronic kidney disease. BMC Nephrol 2018; 19: 285.

23. Lim K, Lu TS, Molostvov G, et al. Vascular Klotho deficiency potentiates the development of human artery calcification and mediates resistance to fibroblast growth factor 23. Circulation 2012; 125: 2243-55.

24. Hu MC, Shi M, Zhang J, et al. Klotho deficiency causes vascular calcification in chronic kidney disease. J Am Soc Nephrol 2011; 22: 124-36.

25. Zheng S, Zheng Y, Jin L, Zhou Z, Li Z. Relationship between serum soluble klotho protein and coronary artery calcification and prognosis in patients on maintenance hemodialysis. Iran J Public Health 2018; 47: 510-8.

26. Cai H, Lu R, Zhang M, et al. Serum soluble klotho level is associated with abdominal aortic calcification in patients on maintenance hemodialysis. Blood Purif 2015; 40: $120-6$

27. Yu LX, Liu QF, Feng JH, et al. Association of soluble klotho level with adverse outcomes in patients on maintenance hemodialysis. Dis Markers 2020; 2020: 4923970.

28. Oh HJ, Nam BY, Lee MJ, et al. Decreased circulating klotho levels in patients undergoing dialysis and relationship to oxidative stress and inflammation. Perit Dial Int 2015; 35: 43-51.

29. Wang N, Ma J, Ren Y, Xiang S, Jia R. Secreted klotho from exosomes alleviates inflammation and apoptosis in acute pancreatitis. Am J Transl Res 2019; 11: 3375-83.

30. Wang T, Li Y, Wu H, et al. Optimal blood pressure for the minimum all-cause mortality in Chinese ESRD patients on maintenance hemodialysis. Biosci Rep 2020; 40: BSR20200858.

31. Gutiérrez OM, Mannstadt M, Isakova T, et al. Fibroblast growth factor 23 and mortality among patients undergoing hemodialysis. New Engl I Med 2008; 359: 584-92.

32. Scialla JJ, Xie H, Rahman $M$, et al. Fibroblast growth factor-23 and cardiovascular events in CKD. J Am Soc Nephrol 2014; 25: 349-60. 